\section{Echographic study of extraocular muscle thickness in children and adults}

\begin{abstract}
Background Echobiometric evaluation of extraocular muscles in normal subjects has been performed previously, but only in adults. We determined extraocular muscle thickness in normal subjects in three age groups. Methods Extraocular muscle thickness was studied in 75 normal subjects divided into three age groups (5-10, 11-15 and 28-37 years) using a Biovision B-scan-S instrument in standardized A-mode (frequency, $10 \mathrm{MHz}$;

The maturation process of the oculomotor system in the period immediately following birth and several genetic and epigenetic factors influencing thickness are known, ${ }^{6-8}$ but no data available regarding the thickness of the extraocular recti muscles during childhood and the developmental process is not known.

The goal of the present study was to evaluate the variations in age-related extraocular recti muscle thickness using echographic measurements.
\end{abstract} biometry resolution, $0.15 \mathrm{~mm}$; depth, 40-60 mm; points on $X$ axis, 512; levels on $Y$ axis, 256). All measurements were performed by the same operator and repeated five times. The reproducibility of the technique was determined using the coefficient of variation. The one-way ANOVA test was used to compare the three groups, and the two-tailed unpaired $t$-test was used to compare subjects aged 5-10 years and those aged 11-15 years, and subjects aged 11-15 years with those aged 28-37 years.

Results The technique showed good reproducibility. In subjects $5-10$ years old, the coefficient of variation was $8 \%$; in subjects 11-15 years and 28-37 years old, it was 5\%. Increased muscle thickness was observed with age $(p<0.001)$. A statistically significant difference between the medial and inferior recti muscles in subjects 11-15 years and 28-37 years old was found $(p<0.001)$.

Conclusions The increased thickness of all recti muscles may be influenced by growth (primarily during puberty), and the variations in thickness of the extraocular muscles may be attributable to near-vision stimulus of the inferior and medial recti muscles.

Key words Echobiometry, Muscle growth, Recti muscles

The thickness of the extraocular recti muscles has been measured by several groups of investigators who used various methodologies; however, the measurements were performed only in adults. ${ }^{1-5}$

\section{Materials and methods}

All participants were recruited from among healthy subjects treated in the paediatric clinic and among the healthy subjects of the general outpatient clinic in our department. All study participants were fully informed about the goal of the research. Consent was obtained from the subjects themselves or, in the case of children, from their parents.

The thickness of the recti muscles were determined echographically in both eyes of 75 healthy subjects ( 38 females, 37 males) who had no evidence of disorders of ocular motility. All participants had a refractive error between -1.5 and +1.0 dioptres and were free from systemic and ophthalmological diseases that could affect the development or growth of the extraocular muscles.

The subjects were divided into three age groups: 5-10 years (46 eyes, 23 subjects), 11-15 years (48 eyes, 24 subjects) and 28-37 years (56 eyes, 28 subjects).

The measurement technique used was that proposed by Ossoinig, ${ }^{2,9,10}$ which allows the transbulbar echographic determination of the maximum thickness of the muscle. The muscle was evaluated in the primary gaze position with the subjects fixating on a light point $5 \mathrm{~m}$ away. The echographic probe was located in the transbulbar position corresponding to the antagonist muscle as close as possible to the equator; the probe was angled posteriorly, thereby shifting the sound beam (sound velocity $1550 \mathrm{~m} / \mathrm{s}$ ) along the underside of the muscle to determine from the graph the maximal, steeply rising, double-peaked sheath spikes. The two

\author{
S. Saccà \\ A. Polizzi \\ A. Macrì \\ G. Patrone \\ M. Rolando \\ Department of Neurological \\ Sciences and \\ Neurorehabilitation \\ Section of Ophthalmology \\ University of Genoa \\ Genoa, Italy
}

Sergio Claudio Saccà, MD Department of Neurological Sciences and

Neurorehabilitation

Section of Ophthalmology

University of Genoa

Ospedale San Martino -

Pad. 9

Largo Rosanna Benzi 10

1-16132 Genoa, Italy

Tel: + 390103538455

Fax: + $390103538494 / 55$

e-mail sacca@smartino.ge.it

Received: 13 September 1999

Accepted in revised form:

21 March 2000 




Fig. 1. Scanning echographic profile of the medial rectus muscle of a 15-year-old female. ' $a$ ' is the scleral peak; the distance between the peaks ' $b$ ' and ' $c$ ' indicates the muscle thickness. Internal peaks indicate internal reflectivity.

spikes represent the muscle wall. The muscle thickness (in millimetres) was determined using electronic cursors positioned at the two superior apices of the spikes (Fig. 1). ${ }^{11}$

The muscles were measured at a tissue sensitivity of $-20 \mathrm{~dB}$. These determinations were performed by a Biovision B-scan-S (BV International, Clermont-Ferrand, France) in standardized A-mode (frequency, $10 \mathrm{MHz}$; biometry resolution, $0.15 \mathrm{~mm}$; depth, $40-60 \mathrm{~mm}$; points on $X$ axis, 512; levels on $Y$ axis, 256) by the same highly experienced operator who repeated each measurement five times. The average and the standard deviation of these five values were then calculated. The coefficient of variation, that is, the standard deviation/mean $\times 100$, of each muscle of each subject was calculated. The averages of all coefficients of variation were then evaluated for the three groups.

The muscle thickness value represents the mean of the five previous measurements and thus the average thickness for eyes within individuals formed the basic unit of measurement. The muscle thickness values were statistically elaborated; the mean, the standard deviation, and the 5th and 95th percentiles were calculated. The one-way ANOVA test was used to compare the three age groups. A two-tailed paired $t$-test was used to study the differences between the right and left eyes and a twotailed unpaired $t$-test was used to study the differences between subjects who were 5-10 years of age and those who were 11-15 years old, and then between subjects who were 11-15 years old and those who were $28-37$ years old.

\section{Results}

The coefficient of variation in the subjects who were 5-10 years old was $8 \%$; it was $5 \%$ for subjects $11-15$ years and 28-37 years old. The results are summarised in Table 1.

Statistically significant differences were found for the increases in thickness of all recti muscles between the subjects aged 5-10 years and those aged 11-15 years, and between the subjects aged 11-15 years and those aged 28-37 years (for details see Table 2).

Table 1. Average, standard deviation (SD), 5th, 50th and 95th percentiles, and range (average $\pm 2 S D$ ) of recti muscle thickness (mm) in the three age groups

\begin{tabular}{|c|c|c|c|c|c|c|c|}
\hline Age group & Average & $\mathrm{SD}$ & 5th percentile & 50th percentile & 95th percentile & Range & Average $\pm 2 \mathrm{SD}$ \\
\hline \multicolumn{8}{|c|}{$5-10$ years ( $n=46$ eyes) } \\
\hline M & 3.12 & 0.60 & 2.33 & 2.97 & 4.11 & 1.92 & 4.31 \\
\hline $\mathrm{L}$ & 3.08 & 0.69 & 2.45 & 3.09 & 4.65 & 1.70 & 4.46 \\
\hline$S$ & 3.48 & 0.60 & 2.74 & 3.52 & 4.65 & 2.29 & 4.67 \\
\hline I & 2.71 & 0.62 & 1.79 & 2.77 & 3.88 & 1.47 & 3.95 \\
\hline \multicolumn{8}{|c|}{$11-15$ years ( $n=48$ eyes) } \\
\hline $\mathrm{M}$ & 3.60 & 0.60 & 2.93 & 3.44 & 4.65 & 2.39 & 4.80 \\
\hline $\mathrm{L}$ & 3.63 & 0.76 & 2.82 & 3.62 & 4.88 & 2.11 & 5.15 \\
\hline $\mathrm{S}$ & 3.98 & 0.98 & 2.99 & 3.99 & 5.27 & 2.03 & 5.94 \\
\hline $\mathrm{I}$ & 3.45 & 0.76 & 2.81 & 3.28 & 4.73 & 1.93 & 4.97 \\
\hline \multicolumn{8}{|c|}{$28-37$ years ( $n=56$ eyes $)$} \\
\hline M & 4.57 & 0.51 & 3.70 & 4.66 & 5.27 & 3.55 & 5.60 \\
\hline $\mathrm{L}$ & 4.11 & 0.65 & 3.68 & 4.04 & 5.04 & 2.81 & 5.41 \\
\hline $\mathrm{S}$ & 4.34 & 0.40 & 4.03 & 4.31 & 4.88 & 3.55 & 5.13 \\
\hline I & 4.16 & 0.45 & 4.81 & 3.59 & 4.11 & 3.25 & 5.06 \\
\hline
\end{tabular}

$\mathrm{M}$, medial rectus muscle; L, lateral rectus muscle; S, superior rectus muscle; I, inferior rectus muscle. 
Table 2. Results of a two-tailed unpaired $\mathbf{t}$-test to compare the median thickness of the recti muscle in the three age groups

\begin{tabular}{lcccc}
\hline & M1 & L1 & S1 & I1 \\
\hline M2 & $p=0.0002$ & - & - & - \\
M3 & $p<0.0001$ & - & - & - \\
L2 & - & $p 0.0002$ & - & - \\
L3 & - & $p=0.0009$ & - & - \\
S2 & - & - & $p=0.0016$ & - \\
S3 & - & - & $p=0.0211$ & - \\
I2 & - & - & - & $p<0.0001$ \\
I3 & - & - & - & $p<0.0001$ \\
\hline
\end{tabular}

$1,5-10$ year age group; $2,11-15$ year age group; 3, 28-37 year ago group; $\mathrm{M}$, medial rectus muscle; $\mathrm{L}$, lateral rectus muscle; $\mathrm{S}$, superior rectus muscle; I, inferior rectus muscle.

The superior rectus muscle was the thickest in the subjects $5-10$ years of age. The medial rectus muscle increased the most in thickness among the three age groups. The percentage increases in muscle thickness of the four recti muscles in the three groups are shown in Fig. 2.

No statistically significant differences were found between the left and right eyes. The differences among the three groups were significant $(p<0.0001$ using the one-way ANOVA test).

\section{Discussion}

Echobiometric measurement of the thickness of extraocular muscles was described for the first time by McNutt et al. in 1977, ${ }^{2}$ after which the technique was routinely used in ophthalmology clinics. ${ }^{1-4}$ The determination of the thickness of extraocular muscles was performed using computed axial tomography and more recently magnetic resonance tomography, which both have yielded results similar to echobiometry. ${ }^{12-14}$ As a result, echobiometry is usually used to follow patients with Graves' disease $e^{5,14,15}$ and other extraocular myopathies ${ }^{16,17}$ instead of radiological examination, which is more expensive and sometimes requires general anaesthesia when children are examined. The validity of the results obtained using this technique have been debated ${ }^{12,13}$ however, many experienced authors agree that it is accurate and reproducible. ${ }^{1,15,17}$

The method used in the present study is the same as that described by McNutt and colleagues; ${ }^{2}$ all measurements were performed by the same operator to avoid inter-operator variability. This resulted in a more than acceptable coefficient of variation. The coefficient of variation was slightly higher $(8 \%)$ in children $5-10$ years of age, probably because they were less cooperative compared with those in the older age groups, in which the coefficient of variation was $5 \%$.

The range of thickness of the extraocular recti muscles detected in the present study in the adult subjects is close to the ranges measured by other authors (Fig. 3). The differences in range among these authors may be attributable to sample variability, differences among the instruments used, the clinical experience of the operator, and the inter-operator variability.

According to Demer and Kerman, ${ }^{12}$ every echographic centre should have its own range of normal values. The purpose of the present study, however, was not to add to the literature another range of normal values for adult healthy subjects, but to cross-sectionally compare three age groups to detect significant changes in the thickness of extraocular recti muscles.

It is noteworthy that older subjects generally have thicker muscles, which suggests muscle growth with age, at least for the three age ranges we evaluated. Our results lead us to theorise that the increase in thickness of each extraocular muscle differs according to the muscle. In fact, we found that the thicknesses of the lateral and superior recti muscles were not highly significantly different when the subjects aged 11-15 years and 28-37 years were compared. In contrast, the thicknesses of the medial and inferior recti muscles in the subjects 11-15 years old were highly significantly different and thinner than in the subjects aged 28-37 years (Table 2).

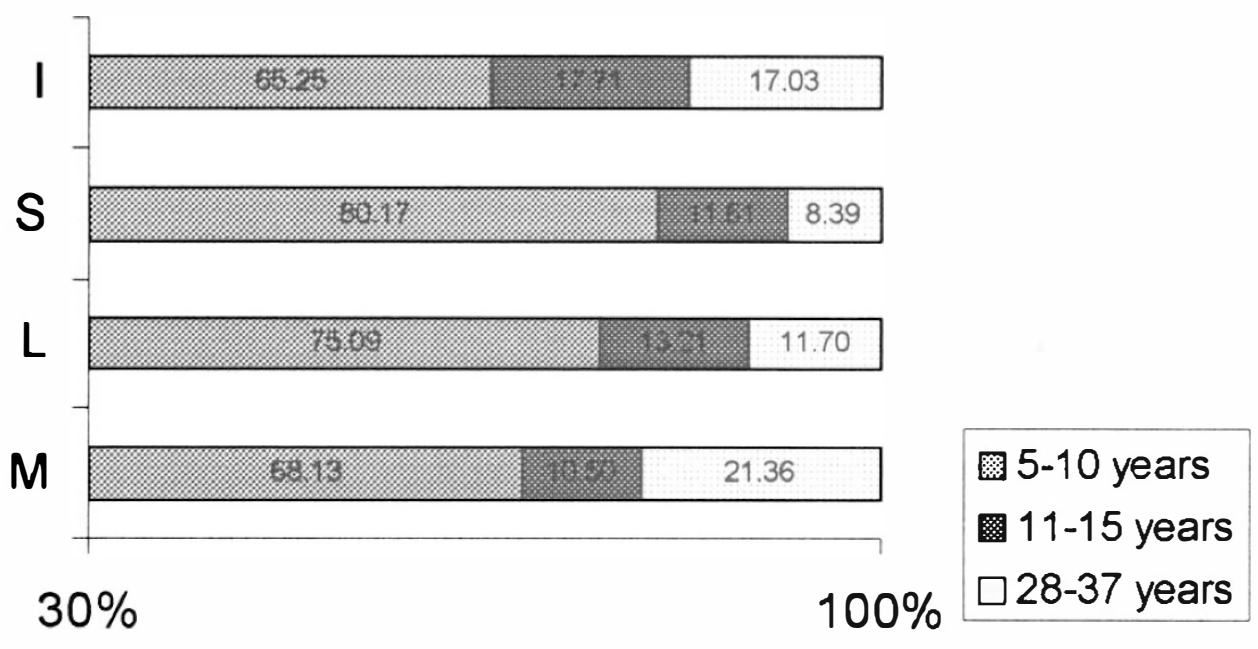

Fig. 2. Taking the muscle thickness measured in the subjects aged 28-37 years as the final thickness, the graph shows the percentage increases in thickness compared with the children aged 5-10 years. The results suggest increases in muscle thickness with age. I, inferior rectus; S, superior rectus; $L$, lateral rectus; $M$, medial rectus. 




Fig. 3. Previously published thicknesses of recti muscles $(\mathrm{mm})$. The different authors have used the same method but employed different sensitivity. 1, Reibaldi et al. ${ }^{3} ; 2$, Byrne et al. ${ }^{1} ; 3$, Komatsu and Tane ${ }^{4} ; 4$, McNutt et al. ${ }^{2} ; 5$, Ossoinig ${ }^{10} ; 6$, current data.

Our findings suggest that the increase in thickness of the superior and lateral recti seems to slow down by age 15 years while the thickness of the medial and inferior recti muscles continue to increase.

Extraocular muscle growth is probably influenced by several factors, namely growth factors, neuronal influences, and the development of the motor visual system in toto. ${ }^{8}$ Nevertheless, the different rates of growth of the extraocular recti muscles suggest a correlation between age and the different uses of these muscles.

During puberty, metabolic and hormonal changes cause modifications of the connective tissue and the muscle fibres. ${ }^{18}$ The growth in muscle thickness is reported to be the result of increases in connective tissue among the muscle fibre. ${ }^{6}$ Therefore, the increases in the thickness of the extraocular recti muscles seen in children 5-10 years old and those in the subjects 11-15 years old are probably the result of incremental increases of ageing, which is similar to that seen in other organs.

However, the growth of the inferior and medial recti also continues after puberty. Therefore, we believe that the well-known concept of structure following function can be applied to these muscles, because, even if the structure is similar, the function is different and the types of fibres also are different. ${ }^{19}$
Drachman ${ }^{20}$ reported that the type of muscle structure is determined by the innervation pattern, with the muscle characteristics being able to adapt to the frequency of innervation or the amount of work to be done. Nevertheless Rosenfeld ${ }^{2}$ indicates that adaption vergence varies with the age and is independent of the tonic innervation.

Furthermore, the hypothesis of McNutt and colleagues $^{2}$ suggests that the medial rectus muscle increase in thickness in proportion to the number of hours spent reading. Therefore, we believe that the stimulus of near vision is the main cause of development of the medial and inferior recti during and after puberty, when the number of hours engaged in reading generally increases. Interestingly, the individuals aged 28-37 years had reached a high level of education (even though it was not an inclusion criterion); $98 \%$ of these subjects had at least passed the college matriculation examination.

The results of the present study indicate that all extraocular recti muscles increase in thickness from childhood, and this development is probably attributable to not only the biological growth of the muscle system but also to the increase in 'functional' thickness of the inferior and medial recti muscles.

The authors thank Lynda C. Charters, Marlboro MA, for editing the manuscript. 


\section{References}

1. Byrne SF, Gendron EK, Glaser JS, Feuer W, Atta H. Diameter of normal extraocular recti muscles with echography. Am J Ophthalmol 1991;112:706-13.

2. McNutt LC, Kaefring SL, Ossoinig KC. Echographic measurement of extraocular muscles. In: White D, Brown RE, editors. Ultrasound in medicine, vol 3a: Clinical aspects. New York: Plenum Press, 1977:927-32.

3. Reibaldi A, Assennato GF, Avitabile T, Uva MG. The echobiometric measurement of extraocular muscles in normal subjects. In: Thijssen JM, editor. Ultrasonography in ophthalmology. Doc Ophthalmol Proc Ser 1988;51:285-90.

4. Komatsu A, Tane S. Ultrasonographic measurements of extraocular muscle thickness in normal eyes and eyes with orbital disorders causing extraocular muscle thickening. Doc Ophthalmol Proc Ser 1995;58:236-46.

5. Tane M, Komatsu A. Echographic measurements of extraocular muscles in normal persons and in patients with thyroid orbitopathy. Proceedings of the Acta XXIV International Congress of Ophthalmology, San Francisco, vol 1. 1982:128-31.

6. Sevel D. Development of the connective tissue of the extraocular muscles and clinical significance. Graefes Arch Clin Exp Ophthalmol 1988;251:226-46.

7. Sevel D. A reappraisal of the origin of the human extraocular muscles. Ophthalmology 1988;88:1330-8.

8. Porter JD, Baker RS, Ragusa RJ, Brueckner JK. Extraocular muscles: basis and clinical aspects of structure and function. Surv Ophthalmol 1995;39:451-84.

9. Ossoinig KC. Standardized echography: basic principles, clinical applications and results. Int Ophthalmol Clin 1979;19:127.
10. Ossoinig KC. The technique of measuring the extraocular muscles. In: Gernet H, editor. Diagnostica ultrasonica in ophthalmologica. Munich: RA Remy, 1979:166.

11. Byrne SF, Green RL. Ultrasound of the eye and orbit. St Louis: Mosby Year Book, 1992.

12. Demer JL, Kerman BM. Comparison of standardized echography with magnetic resonance imaging to measure extraocular muscle size. Am J Ophthalmol 1994;118:351-61.

13. Holt JE, O'Connor PS, Douglas JP, Byrne B. Extraocular muscle size comparison using standardized A-scan echography and computerized tomography scan measurements. Ophthalmology 1985;92:1351-5.

14. Mann K, Schoner W, Maier-Hauff K, Rothe R, Jungst D, Karl $\mathrm{HJ}$. Comparative examination of endocrine ophthalmopathy by means of ultrasonography, computerized tomography and FISH bioassay. Klin Wochenschr 1979;57:831-7.

15 . Byrne SF. Standardized echography of the eye and orbit. Neuroradiology 1986;28:618-40.

16. Ossoinig KC, Hermsen VM. Myositis of extraocular muscles diagnosed with standardized echography. In: Hillman JS, Le May MM, editors. Doc Ophthalmol Proc Ser 1984;38:381-92.

17. Dick AD, Nangia V, Atta H. Standardised echography in the differential diagnosis of extraocular muscle enlargement. Eye 1992;6:610-7.

18. Daughaday WH. Growth hormone: normal synthesis, secretion, control and mechanism of action. De Groot Endocrinol 1989;1:318.

19. Scott AB, Collins CC. Division of labor in human extraocular muscle. Arch Ophthalmol 1973;90:319-22.

20. Drachman DB. Neuromuscular transmission of trophic effects. Ann NY Acad Sci 1971;183:158-70.

21. Rosenfield $M$. Tonic vergence and vergence adaptation. Optom Vis Sci 1997;74:303-28. 